\title{
Physical activity, BMI and cancer prevention in urban adults
}

\author{
Sally N Akarolo-Anthony ${ }^{1 *}$, Clement A Adebamowo ${ }^{2}$ \\ From Metabolism, diet and disease \\ Washington, DC, USA. 29-31 May 2012
}

\section{Background}

Developing countries are undergoing epidemiological transitions with increasing prevalence of Non-Communicable Diseases (NCD) particularly cancers. In many African countries, poor lifestyle choices including dietary patterns, lack of physical activity and weight gain contribute to the risk factors of many cancers. In this study, we evaluated physical activity, carbohydrate intake and anthropometric measurements in an urbanized Nigerian population. Our objective was to measure the prevalent lifestyle, as well as develop and disseminate adequate educational strategies based on our findings, to alleviate the problem in the population.

\section{Methods}

1059 workers at a government office in Nigeria answered an interviewed administered questionnaire and had anthropometric characteristics measured in a study of body size, dietary energy intake and physical activity in 2010 .

\section{Results}

In our study population, the mean age (SD) of participants was 41.5 (9.3) years and mean BMI (SD) was 27.0 (4.9). $36 \%$ are overweight and $25 \%$ are obese. $58.9 \%$ reported that they don't exercise, $11.2 \%$ exercise 1day/ week, $8.7 \%$ exercise 2 days/week and $21.2 \%$ exercise at least 3days/week. 55\% spend at least 6 hours/week sitting at home watching TV, $51 \%$ spend at least 6 hours/ week sitting doing other things. $>90 \%$ don't spend any time on sports (running, biking, tennis, squash, soccer, swimming, hiking, aerobics, and weights). $24 \%$ spend $>10$ hours/week walking or standing at home, while $67 \%$ spend $>10$ hours/week working at home.

'Nutrition Department, Harvard School of Public Health, Boston, MA, 02215, USA

Full list of author information is available at the end of the article

\section{Conclusion}

Our result shows urbanized Nigerian adults adopt a sedentary lifestyle and are more physically active while executing housework than while away from home. As obesity and physical inactivity are modifiable risk factors for NCD, adults should be encouraged to engage in culturally acceptable lifestyle activities that will prevent obesity and promote physical activity as a modality to reduce NCD's especially cancer incidence in Africa.

\section{Author details}

${ }^{1}$ Nutrition Department, Harvard School of Public Health, Boston, MA, 02215, USA. ${ }^{2}$ Epidemiology and Public Health, School of Medicine, University of Maryland, Baltimore, MD, 021201, USA.

Published: 27 June 2012

doi:10.1186/1753-6561-6-S3-P69

Cite this article as: Akarolo-Anthony and Adebamowo: Physical activity, BMI and cancer prevention in urban adults. BMC Proceedings 20126 (Suppl 3):P69.
Submit your next manuscript to BioMed Central and take full advantage of:

- Convenient online submission

- Thorough peer review

- No space constraints or color figure charges

- Immediate publication on acceptance

- Inclusion in PubMed, CAS, Scopus and Google Scholar

- Research which is freely available for redistribution
() Biomed Central
C Biomed Central 